\title{
Allocation of the geo-dynamically hazardous zones during intensive mining of flat-lying coal seams in the mines of SUEK-Kuzbass JSC
}

\author{
Evgeny Yutiaev ${ }^{1}$, Anatoly Meshkov ${ }^{1}$, Anton Popov ${ }^{2}$, and Arcady Shabarov ${ }^{2}$ \\ ${ }^{1}$ SUEK-Kuzbass JSC, 652507, Kemerovo region, Leninsk-Kuznetsk, Vasilyev str., 1 \\ ${ }^{2}$ Saint-Petersburg Mining University, 199106, Saint-Petersburg, Line $21^{\text {st }}$, V.I., building 2
}

\begin{abstract}
Hazardous and ineffective mines were closed, and a number of underground and strip mines of a modern technological level were built as a result of the restructuring of the coal industry in Russia. However, safety in the coal mines continues to be one of the urgent issues nowadays. In underground coal mining, the main types of risks are processes occurring in the rock mass as a result of mining operations. It is necessary to realize timeous and the most accurate prediction of harmful events, which occur during a development of coal fields, to increase the efficiency and reduce the cost of coal mining. The most optimal and, at the same time, comprehensive approach to predicting possible natural hazardous events in the process of modern coal mining are considered in this article. The results of implementation of integration of different methods of geodynamic and geomechanics researches are presented in this paper.
\end{abstract}

\section{General terms}

Until quite recently, it was believed that mainly technological reasons were the cause of the vast majority of accidents and their extent of damage. However, the practice of construction, operation and conservation of industrial facilities and productions associated with the development and usage of subsoil and land surface has shown that the effectiveness and safety of their functioning can be ensured only with the preliminary identification and assessment of geodynamic processes occurring in geological environment. It can also be achieved by assessment of natural and technology related risks, including environmental review and monitoring of geodynamic processes.

\section{Allocation of geo-dynamically hazardous zones based on the integration of geodynamic and geological and structural methods}

Prediction and assessment of hazardous geodynamic processes are carried out on the basis of the geodynamic zonation. Geodynamic zonation is a method of studying the block structure, stress and gas-hydrodynamic states of a rock mass; it is a method of identifying, evaluating and monitoring currently active raptured tectonic displacements - active faults, 
geodynamic zones and associated risk zones, in order to increase the geodynamic and environmental safety of industrial and civilian facilities during the development of mineral resources and land surfaces $[1,2]$.

Modern tectonics considers four main types of major geodynamic regimes. Segregation of these regimes is founded on the basic concepts of plate tectonics, and this segregation is associated with variations in plate motions. There are regimes of prevalence of compressive horizontal stresses, tensile horizontal stresses, shear stresses, and, finally, prevalence of compressive or tensile vertical stresses [3-4].

Aforementioned geodynamic regimes, presented within the fields as a whole and the mines particularly, determine the tendency of the territories under development to the occurrence of emergency situations of a different nature.

The analysis of geodynamic safety includes the process of identifying geodynamic hazards, assessing the frequency (or probability) of their occurrence and assessing the effectiveness (adequacy) of the applied preventive measures to manage (minimize) geodynamic risks.

Firstly, assessment of the geodynamic state of the rock mass blocks is carried out within the mining allotment of a coal field, and then the selection of a list of hazardous events takes place. It is necessary to conduct risk analysis of geodynamic hazards for these events.

Next, identification of the types of geodynamic hazards is executed. This measure is designed to establish the presence or absence of a geodynamic hazard in the mine. A description of all types of geodynamic hazards in the considered mine is presented. A list of possible types of geodynamic hazards that may occur during the mining is given. Cause and effect relationships for emergencies are established according to the characteristic of the source of the occurrence of the geodynamic hazards (stressed rocks, gas pressure, seismic waves, shaking deformation, water pressure, etc.).

A hazardous geodynamic event is an event of natural or man-made origin, or a result of natural, man-made and anthropogenic-produced geodynamic processes; these processes can cause an emergency in anthropogenic and natural systems [4-5].

A characteristic of geological and mining conditions (their combinations) are given for each type of the geodynamic hazard.

The main methodological principle of geodynamic zonation is based on a system approach - integration, continuity and coordination of working scale from the general to the particular. Zoning according to the risk of emergencies at the regional, district and local levels is uniform, regardless of the working scale.

Base, peak, residual, difference and goniobasis surfaces of various orders are obtained from topographic maps of different scales, and then they are compared to the data of the whole system of available geological, geophysical, geochemical and geodynamic data. Currently, morphometric analysis of these compared surfaces allows revealing tectonic faults and structures of various orders and their motions, both in platform and folded areas.

However, it was found that within the mine fields during the exploration and development of coal deposits, as well as during observations to solve various problems, in particular, when determining the basic values of the process of deformation of land surface as a result of underground mine workings and predicting the zones of collapses and screes occurring in mines, emanations of a linear character of localization can be detected in areas (zones) where according to geological and exploration data there are no tectonic faults. Moreover, the nature of emanations is similar to abnormalities above tectonic faults [6-7].

These geodynamic zones are associated with processes, which occur in the overburden as a result за their current deformations. Stress fields are responsible for changes in magnetic, electromagnetic, atmochemical, physical and mechanical and other properties of geological environment. 
The upper levels of the soil mass to a depth of 10-15 $\mathrm{m}$ are experiencing reciprocating motions along three spatial axes.

The amplitude of vertical movements of the land surface varies between 10-30 mm, depending on the density of soils. The relative horizontal displacement of two fairly close points of the land surface reaches $70 \mathrm{~mm}$ [8]. In addition to the above, the greatest movements are observed within geological discreteness - faults, folds, fractured zones, fractures.

Features of rock bedding: fractured zones, buried residual topography, discordant occurrence of rocks, - or industrial processes associated with operation of mining facilities are considered to be the reason for the appearance of active geodynamic zones within the mine that are not related to fault.

The structure of deep-seated rocks is defined by the presence of buried residual topography, which is not expressed on topographic maps, but is revealed as a result of subtraction of the base surface from the hypsometric, moreover, their structure can be described by the presence of areas of discordant occurrence of rocks [8]. These abnormalities of the structure of the coal-bearing rock mass are effectively determined using methods of geological and structural simulation.

An example of the results of morphostructural analysis of the territory is presented in the form of a map of faults of rank V, zones of influence of active faults of rank III-IV, determined as a result of morphostructural analysis on a topographic base of a scale of 1:2000, and lineaments (Fig. 1).

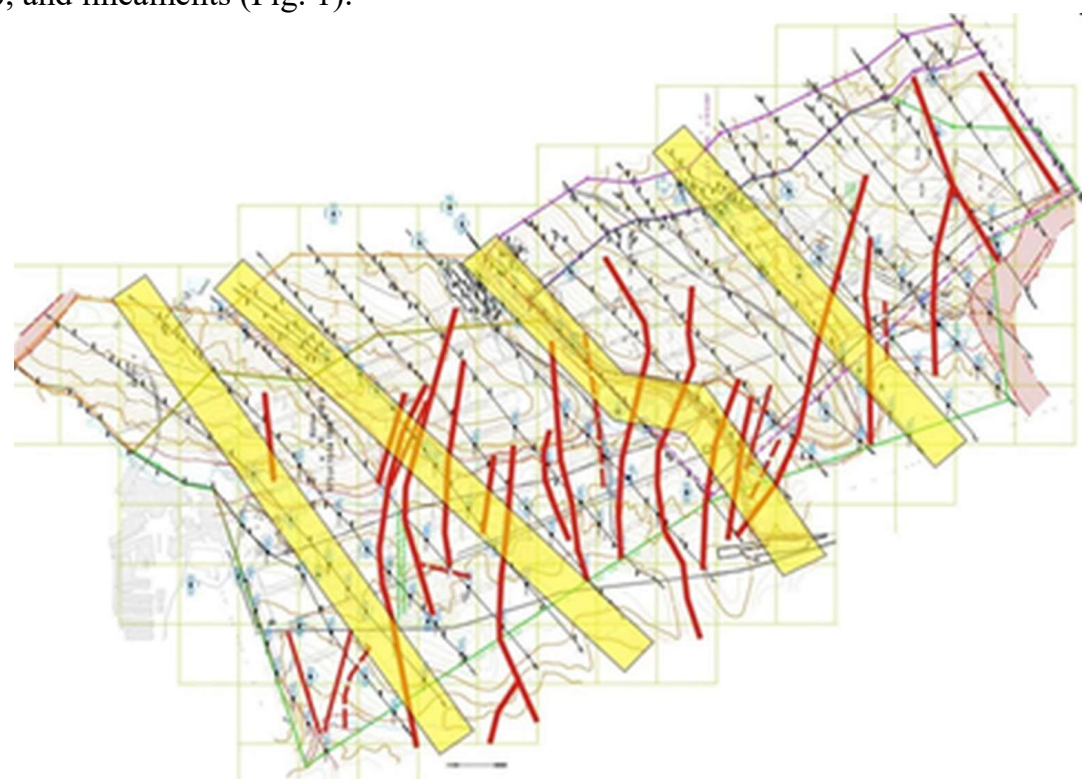

Fig. 1. A map of faults of rank V, zones of influence of active faults of rank III-IV, determined as a result of morphostructural analysis on a topographic base of a scale of 1:2000, and lineaments (minefield n.a. V.D. Yalevskogo).

Faults are shown in red. Yellow color is designated to zones of active faults of rank IIIIV and lineaments.

Intense tectonically stressed zones (TSZ) are associated not only with single faults, but also with systems of faults. The most dangerous structures, which form intense TSZ, were revealed. These primarily include systems of echelon-like faults, fault convergences, partition at sharp angles $\left(10^{\circ}-15^{\circ}\right)$, and wedge-shaped structures. 
Local TSZ are also formed in the places of pinches and swells of the seams and any significant changes in their hypsometry.

Therefore, tectonically stressed zones (TSZ) are mainly confined to the faults of block rock mass; their potential danger is determined by neotectonic activity, morphology, and structure of the fault displacer, as well as the direction of rock deformation under the displacement of the side of the fold. There are two main types of TSZ associated with faults, differing in geological features and natural stress state.

Zones of type I are adjacent to those sections of faults, in which displacer is in the form of tightly closed fracture surrounded by an area with small number of fault fractures; it is described by a high level of tectonic stresses, low porosity and humidity, increased values of strength characteristics and Young modules of rock mass, as well as by a high level of electromagnetic emission.

Zones of type II are separated from the displacer by a disturbed and relieved area; it is described by significantly lower stresses and changes in the state and properties of rocks than in zones of type I [9-10].

The geodynamic zonation technique is not used to identify separate, independent, and randomly distributed lineaments and faults; the feature of this technique is the identification of regularly ordered and ranked systems of faults, which are characteristic of the selected region (district) and reflect allied and hierarchical distribution of stress fields and display in basement and sedimentary cover deformations.

\section{Three-dimensional structural and geological simulation of minefields}

The results of geodynamic zonation were compared to the simulation results. Structures identified during zonation process were discovered and confirmed. An analysis was carried out to indicate forms of manifestation of lineament structures of rank III-V in the morphology of coal seams and to indicate changes in thickness of seams. These data provided the basis for further identification of risk zones, which are planned to be exposed during the development process of the mine.

Initially, a number of operations, which are necessary for the thorough preparation of the initial data at the core of the model, were carried out during simulation process of the minefield.

All of the geological information available today: geological profiles, geological maps, tectonic frameworks, coring data, data of geophysical studies, sketches of mines, - was used to develop geological and structural model of the field.

A common database of exploration wells drilled within the scope of the mining allotment of the minefield was formed as a part of the model development process. A unique code, that is uniform for the entire area, was assigned to each lithological variety identified during drilling. 


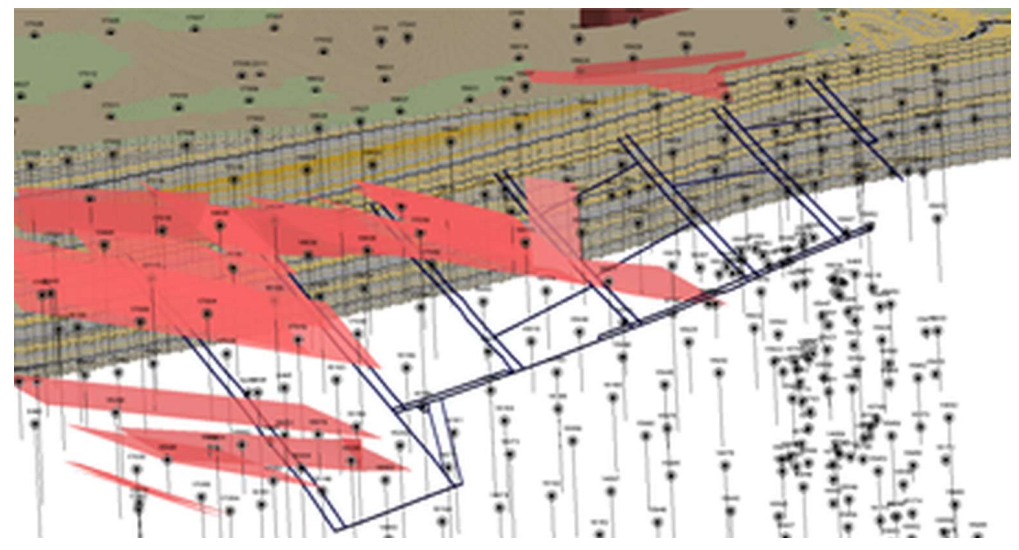

Fig. 2. The block model of the minefield with faults and mine workings of seams 50 and 52.

This was followed by the development and generation of a mesh of the marker horizon, where the block size for the further model was determined. The accuracy of the model depends on the block size - the smaller the block, the more accurate the model will be. The selection of the optimal size of the building block is the main difficulty at this stage of the simulation process due to the fact that the calculation can take several days for small sized blocks.

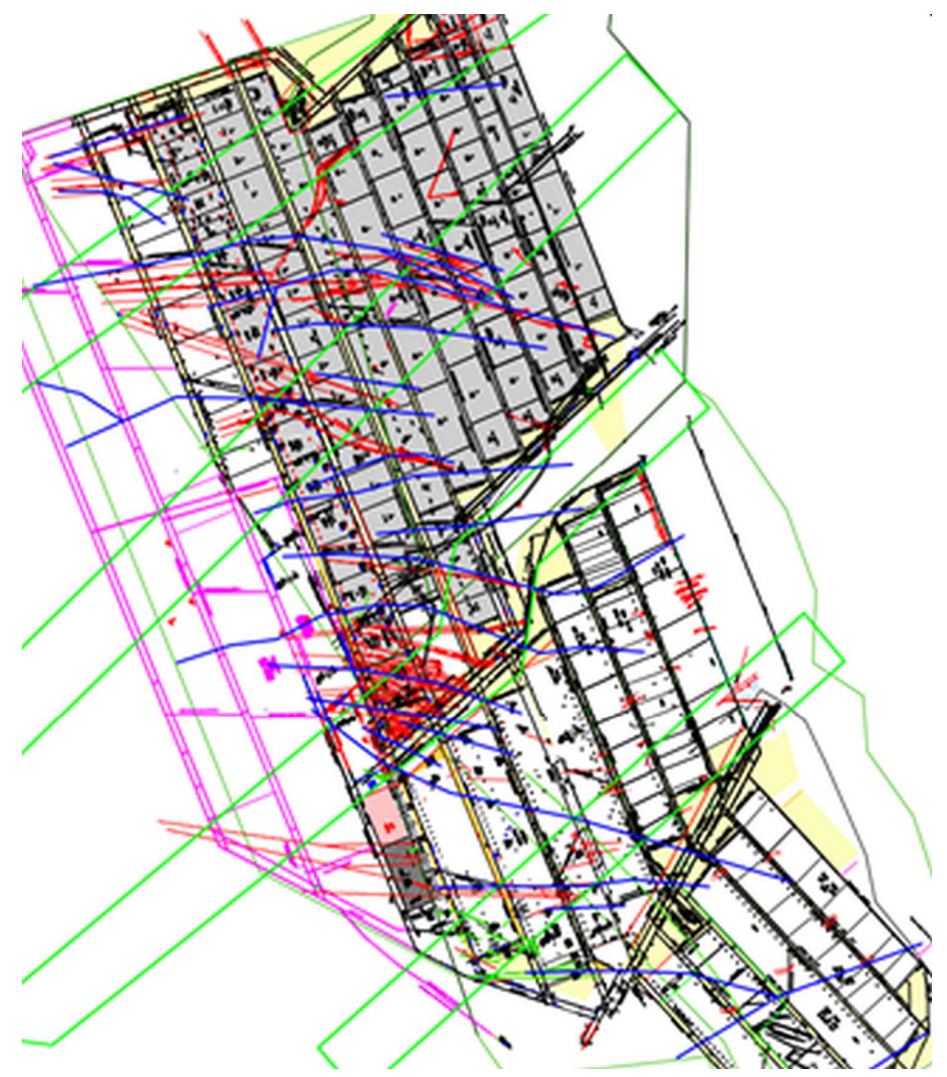

Fig. 3. Conformation of faults identified during zonation and simulation processes.

The results of geodynamic zonation on the surface were coordinated with discovered faults in the roof and the bottom of coal seams during the development process of the three- 
dimensional model of the fault displacer within the minefield. It is worth noting that all the faults indicated in the modern topography and confirmed by the geodynamic zonation are exposed in the coal-bearing stratum (figure 2). In figure 2, the red color indicates the faults identified during zonation process, the green lines correspond to the zones of influence of active faults, the red ones indicate faults that were confirmed during the development and exploration of the field; the azimuths and slope angles of the faults and fault zones are almost completely maintained.

The result of the development process of the three-dimensional model of the minefield is the correspondence between the results of the geodynamic zonation, the fact of the coalseam uncovering and the position of the fault displacer in the block model of the minefield. The obtained results are presented in figure 3.

\section{Geodynamic model of the minefield}

Geometric layout of the numerical model, which includes the existing topographic surface of the field region, working coal seams No. 50 and No. 52, two large-scale faults and tectonic faults of a lower rank, is presented in the figure 4.

The existing topography of the region was taken into account during the development process of the numerical model. The area of the mine "n.a. V.D. Yalevskogo" has a landscape close to plain-like, and does not have any significant difference in elevation. However, taking into consideration the relatively shallow depth of working coal-seams, even a slight difference in elevation (up to 100 meters) can have a significant impact on the natural stress state of the rock mass. Therefore, idealization of the land surface and its approximation to the plane can substantively simplify the numerical model, but, at the same time, it can lead to a distortion of the simulation results.

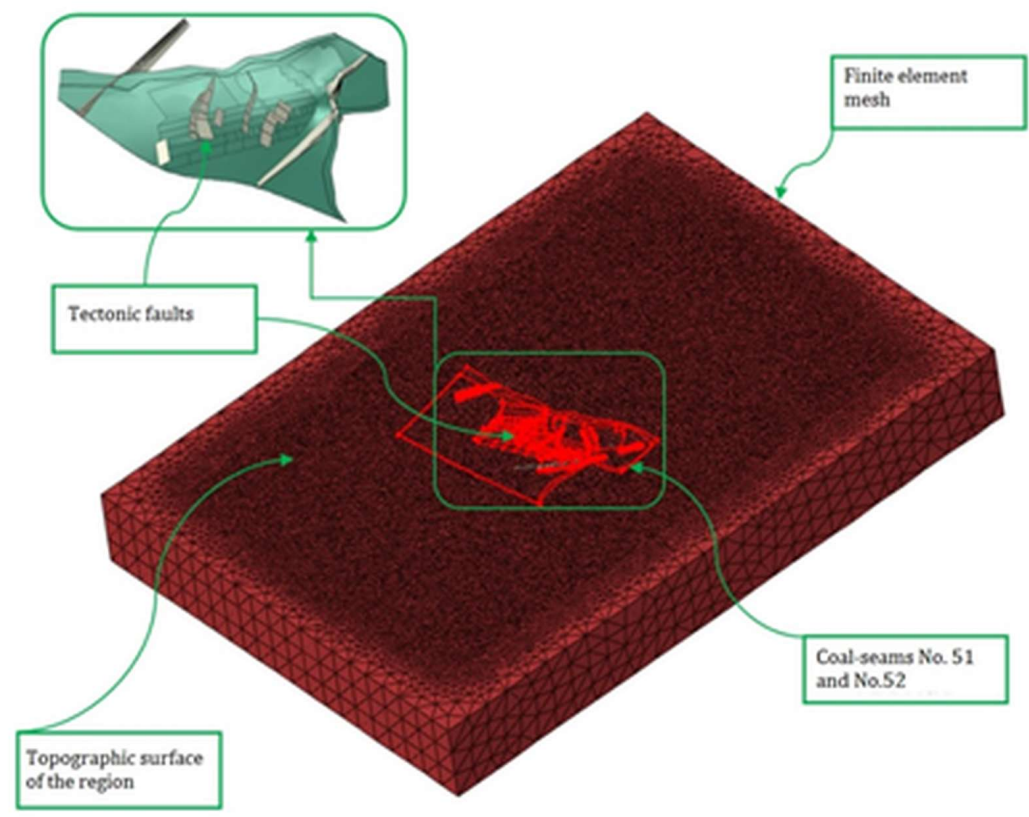

Fig. 4. Geometric layout of the numerical finite-element model of the mine "n.a. V.D. Yalevskogo".

Isochromatic curves of the initial stress field in the rock mass, which were obtained as calculation results, for coal-seams No.52 and No.50 are presented in the figure 5 . 
Tectonic faults, which were indicated during geodynamic zonation of the minefield, have a significant impact on the redistribution of the maximum principle stress conditions in the rock mass.

The natural stress field of the mine is classified as a gravity type. Nevertheless, the isochromatic curves in the figure 5 show the areas, which have stress spikes and relieved zones.

Quantitative analysis of the stress state of the mine n.a. V.D. Yalevskogo suggests that the average value of the principle compression stresses, which are outside the zones of influence of the tectonic faults, does not exceed 3.0-3.5 MPa in the areas planned for stoping.

A)

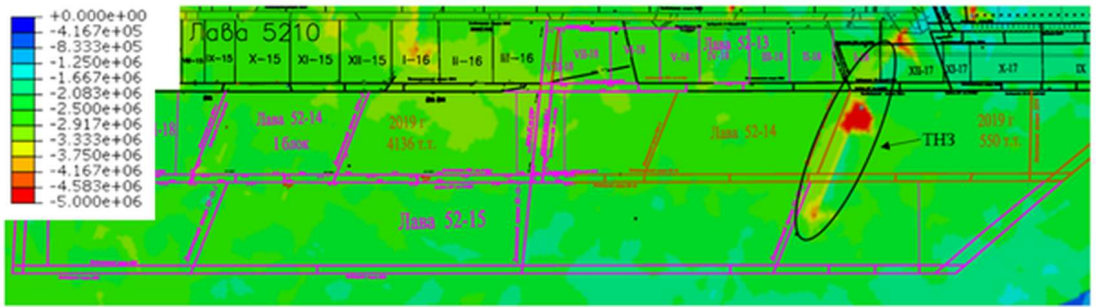

B)

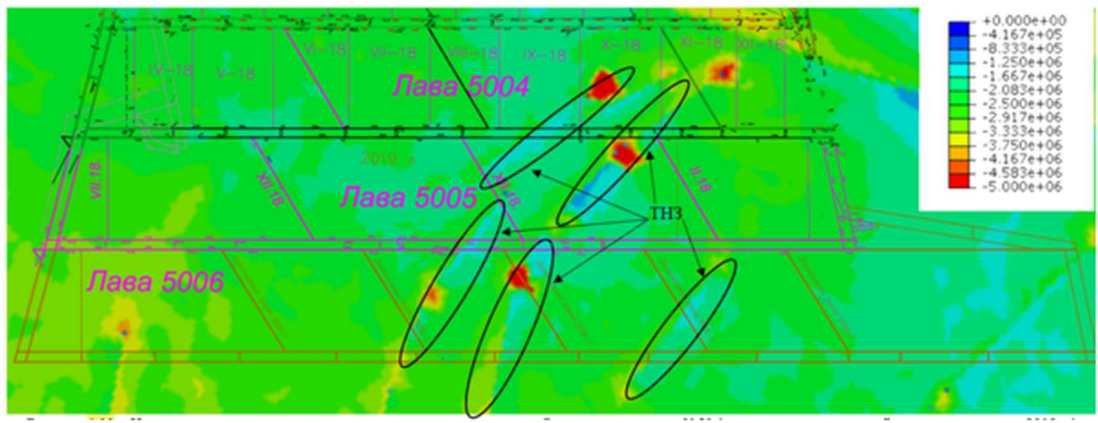

Fig. 5. Isochromatic curves of the distribution of maximum principle stresses in coal-seams of the mine "n.a. V.D. Yalevskogo" (areas planned for stoping until 2019): A) seam No.52; B) seam No.50.

\section{The allocation of tectonically relieved and stressed zones, and prediction of the geodynamic and geomechanical conditions}

The prediction of the geodynamic and geomechanical conditions of minefield's areas, which are planned to be mined, is carried out on the basis of a comprehensive analysis of risks of hazardous geodynamic events according to the distribution and the rank of hazardous zones within the scope of the estimated area.

The main criteria for assigning risk zones to the existing plan of mining operations for coal-seams of the minefield were the results of mathematical simulation and the development of the geodynamic model, the results of the geodynamic simulation.

The general approach of identifying existing risk zones for the predicted areas of the minefield, which are going to be developed in the near future, consists of overlaying all existing forecast maps on a plan.

It is also worth noting that the actual segregation of the tectonically relieved zones (TRZ) and tectonically stress zones (TSZ) was carried out roughly. This segregation was based on the distribution fields of the principle stresses in the initial state of the rock mass, 
id est before the start of mining operations. A layout and general principles of the formation of TRZ and TSZ during stoping, which take into consideration the impact of the mining operations on the neighboring areas, were provided in the text above. Limits of the hazardous zones are most clearly identified using calculations.

However, the indication of the predicted risk zones was carried out on the basis of the geodynamic model for the initial stress fields due to the fact that the position and spatial configuration of the limits of the hazardous zones (LHZ) are unstable. The position and spatial configuration of the LHZ depend on the state of the mining and stoping processes at the current time. The results of the introduction of risk zones to the plan of mining operations for the seam No.52 are presented in the Fig. 6.

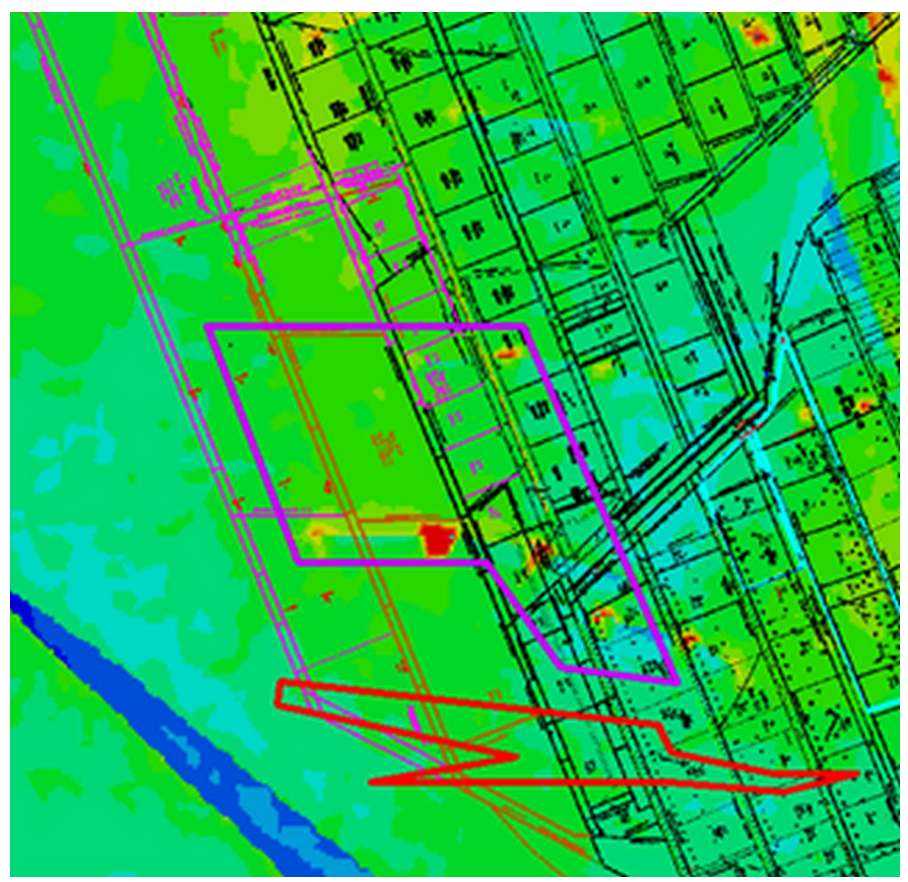

Fig. 6. Introduction of risk zones based on the data of mathematical modeling and comprehensive analysis using neural network to the predicted area of the seam No.52.

It is shown in the figure 6 that the main risk zones within the scope of the predicted area are located in the zone of influence of the tectonic faults, which form the TRZ (based on the distribution of the stress fields in the figure) in their upthrow side and the TSZ in their lying side.

\section{Conclusions}

It is necessary to implement measures to reduce geodynamic risks for effective and safe application of modern technologies for intensive coal mining.

In general, the process of identification and minimization of geodynamic risks involves: - conducting of geodynamic zonation, identification of potentially hazardous zones and consideration of the obtained results for mine layout and planning of mining operations; - implementation of geodynamic monitoring and routine analysis of geodynamic risks; - carrying out measure to prevent accidents due to the manifestation of geodynamic hazards. 
The method of geodynamic zonation, which was used to indicate geo-dynamically hazardous zones during intensive mining of flat-lying seams of Kuzbass, has positively established itself. In addition to morphostructural analysis, neural networks can be applied and calculations of the strain-stress state during stoping can be conducted for more accurate assessment.

The presence of tectonically relieved zones (TRZ) is the most significant geomechanical property at the currently prevailing mining depth of $200-400 \mathrm{~m}$ for planning technological solutions and measures to manage the state of the rock mass.

The locations and limits of these zones can be determined both by office studying of the geological and geomorphological information, and by using full-scale geophysical methods.

It is preferred to locate development workings, setup and recovery rooms outside the TRZ and the TSZ during mine layout with preliminarily allocation of these zones.

To reduce the harmful impact of the TRZ and TSZ on the stoping it is recommended to identify these zones in a timely manner at the planning stage, and to provide ground supports, which move together with the active post immediately after the formation of the outcrop with the pass of the mining machine, in the timbering plan and the plan of strata control in the face.

It is necessary to correct some parameters of the gas drainage process, as well as ground control management plan in the zones of TRZ and TSZ.

\section{References}

1. Fan Chen Anye Cao, Linming Dou, Guangcheng Jing, Geosciences Journal, 3, 1-16 (2019)

2. V. Kecojevic, Z. M. Nor, Journal of Coal Science and Engineering (China), 15:1, 1-6 (2016)

3. T.V. Gudkova, A.V. Batov, V.N. Zharkov, Model Solar System Research, 51:6, 457478 (2017)

4. M. Burša, K. Pěč, Gravity Field and Dynamics of the Earth, 1, 207-244 (1993)

5. A.M. Suchowerska, Geomechanics of singleseam and multi-seam longwall coal mining (University of Newcastle, Newcastle, 2014)

6. S.S. Peng, Coal Mine Ground Control (West Virginia University, Redmond, 2008)

7. A.M. Suchowerska, R.S. Merifield, J.P. Carter, International Journal of Rock Mechanics and Mining Sciences, 61, 306-320 (2013)

8. Australasian Ground Control in Mining, A case study on mine subsidence due to multiseam longwall extraction. URL: https://www.ausimm.com.au/publications/epublication.aspx?ID=12459

9. Ki-Dong Kim Saro Lee, Hyun-Joo Oh Jong-Kuk Choi Joong-Sun Won, Environmental Geology, 50:8, 1183-1191 (2006)

10. Instruction for safely mining development at mines, extracting coal seams, liable to rock bursts (MSHA, Moscow, 2000) 